\title{
ADEQUACY STUDY OF HYBRID MODEL FOR AMMONIA PLANT PROCESSES
}

\author{
G. Oberauskas, V. Galvanauskas \\ Department of Automation, Faculty of Electrical and Electronics Engineering, \\ Kaunas University of Technology, \\ Studentu St. 48-320, LT-513687 Kaunas, Lithuania
}

\begin{abstract}
Peculiarities of ammonia production technology chemical process modeling and identification of hybrid mathematical model parameters are described. Presented hybrid models for ammonia production processes using mass balance equations and artificial neural networks instead of mechanistic absolute reaction rate models. Hybrid models of chemical processes (absolute reaction rates) identified by sensitivity equations using artificial neural networks ANN. The hybrid model adequacy results are presented and discussed.
\end{abstract}

Keywords - process modeling, model adequacy, system validation, chemical technology, system identification, artificial neural networks (ANN).

\section{INTRODUCTION}

Ammonia is widely used in other manufacturing plants, such as paints, cosmetics, synthetic fibers, paper and leather processing, wood and metal surface treatment plants, rubber, latex and electronics.

Experimental data of various technological modes of industrial chemical processes are archived in computerized data warehouses. Using the aforementioned experimental data, artificial neural network (ANN) models can be developed. Empirical models, such as ANN models, are suitable for use when sufficient process experimental data are available. Otherwise, the ANN model may have poor extrapolation Xiong et al. (2005). The hybrid model is a combination of mechanistic and empirical models Psichogios et al. (1992). In chemistry, for example, the mass balance equations that make up the mechanistic model are combined with ANNs, which describe the rates of chemical reactions. Such mathematical models of various structures are used to solve the tasks of ammonia production process modelling and control Khorsand et al. (2007) and Dashti et al. (2006).

The chemical processes of ammonia production are complex and the technological parameters measured in them vary little within the measured scale. This causes difficulties in selecting an appropriate algorithm for identifying the parameters of a hybrid mathematical model. Parameter identification methodology Simutis (1997) based on evolutionary programming or genetic algorithms is widely used in practice Porto et al. (1995) and Na et al. (2002). These algorithms are accurate enough, but require a large number of iterations, which is impractical when using complex hybrid models due to lengthy computations. The sensitivity equation method is widely used to identify hybrid models of biochemical and chemical processes Schubert et al. (1994) and
Galvanauskas et al. (2007). This method does not require a large number of iterations to reach the extremity point.

Chemical processes are sent with nonlinearities Kamesh et al. (2017), thus most commonly used chemical process control systems, which can maintain the technological accuracy required for process parameters Nguyen et al. (2015). In this case, a pressing task arises to develop automatic control systems for chemical processes that would ensure the required quality of regulation of technological parameters, using a priori process information and available direct process measurements Kamesh et al. (2017).

In recent years, hybrid modeling and control methods and hybrid systems have been increasingly used in the development of process control systems Simutis (1997) and Galvanauskas et al. (2007). Hybrid systems combine: mechanistic models, classical mathematical models, models based on fuzzy set methods, and dependencies obtained with the help of artificial neural networks and process experts, which are applied to solve real industrial process control problems Schubert et al. (1994) and Zamaniyan et al. (2013).

\section{STRUCTURE OF HYBRID MODEL}

Mass balance equations are developed for all major ammonia production processes, i. e. secondary reforming, shift conversion, $\mathrm{CO}_{2}$ removal, methanation. The detailed process for the production of basic ammonia can be found elsewhere SC "Achema" (2006). Also, the mass balance equations were developed for basic ammonia production processes based on chemical equilibriums SC "Achema" (2006). Mechanistic model of ammonia production is based on the mass balances equations for the components derived from chemical equilibriums SC "Achema" (2006). The dynamic mass balance equation of the following type for each component was created and numerically solved:

$$
\frac{d\left(C_{N}\right)}{d t}=r_{N}+\left(C_{N i n}-C_{N}\right) \frac{F}{V},
$$

where $r_{N}$ - absolute reaction rate. $[\mathrm{mol} / \mathrm{l} / \mathrm{s}] ; F-$ flow to the chemical process, [1/s]; $V$-volume of vessel, [1]; $C_{N}$ - modeling component concentration, $[\mathrm{mol} / \mathrm{l}] ; \quad C_{N i n}-$ component concentration to process, $[\mathrm{mol} / \mathrm{l}]$.

In this case, instead of mechanistic models describing absolute raction rates, models of artificial neural networks are developed to describe absolute reaction rates. For identification of hybrid model parameters the sensitivity equation technique was applied Simutis (1997). A general flow chart for the identification of the ammonia production process using the 


\section{International Journal of Engineering Applied Sciences and Technology, 2020 \\ Vol. 5, Issue 2, ISSN No. 2455-2143, Pages 8-13 \\ Published Online June 2020 in IJEAST (http://www.ijeast.com)}

sensitivity equation method is provided in Fig. 1, where Inputs $M$ are inputs of the mechanistic model, Inputs ANN are inputs of ANN. The main problem with this combination is that the usual ANN training (parameter identification) procedures may not work or their performance may be significantly reduced. Thus, it is necessary to use different training procedures.

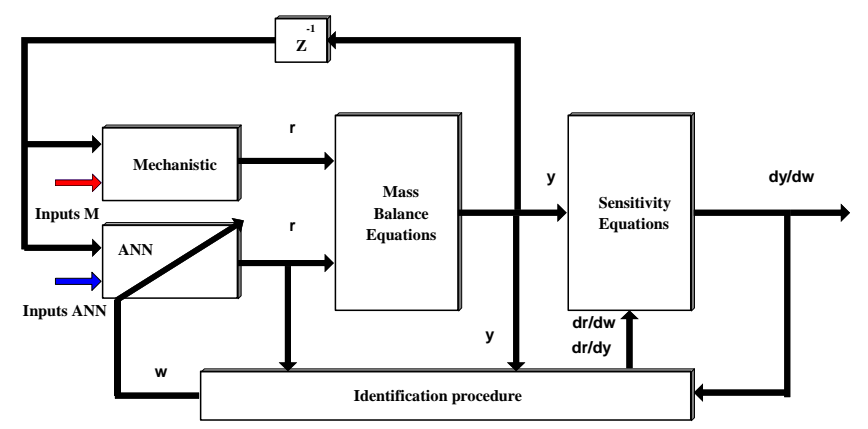

Fig.1. A general flow chart for the identification of the ammonia production process

Experimental data are used for ANN training, which is stored in the computerized database of the ammonia plant SC Achema. In order for the training procedure to be correct and accurate, the experimental data collected under the extreme conditions of the ammonia production process (start / stop of production) are used. The experimental data are standardized to reduce the numerical calculation errors of the identification procedure. Training and testing procedures are applied in the work to assess the quality of ANN training. After training artificial neural networks with experimental data, ANN is tested with other analogous data. To evaluate the efficiency of the hybrid model, the mean square error (RMSE) between the modeled and experimental values was chosen during testing.

The structure of absolute reaction rate models using ANN for ammonia production processes is presented Fig.2.

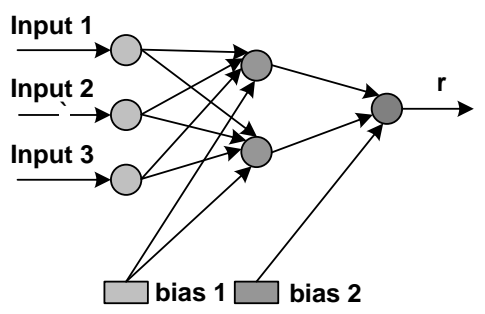

Fig. 2. Typical structure of an ANN for modeling absolute reaction rate

ANN general structure shown in Fig.2 is used for all process in ammonia production. Also, the modeled absolute reaction rates $r_{i}$ are related to the ANN inputs, which are usually the most important technological parameters describing the process dynamics, such as concentrations and flows (to processes), process temperature.
Due to complexity of functional relationship modeling absolute reaction rates it is expressed by a feed forward sigmoid artificial neural network (ANN). Each ANN consists of 3 inputs, 2 nodes in a hidden layer, and 1 output. Including bias values, each ANN will have 11 free tunable model parameters.

The measured parameters of the ammonia production processes are delayed, especially the flow and temperature parameters. It is therefore necessary to estimate the delay in the ANN hybrid model identification procedure. ANN training data is very different. For example, during the methanation process, the $\mathrm{CO}$ concentration is about $10-8 \mathrm{~mol} / 1$ and the temperature is $\sim 320^{\circ} \mathrm{C}$. In addition, some experimental data vary relatively little, for example, the process temperature varies from $317^{\circ} \mathrm{C}$ to $325{ }^{\circ} \mathrm{C}$. Thus, in order to obtain better process identification results, the data normalization procedure is applied to all ANN inputs.

\section{MODELING RESULTS}

ANN parameters were identified using the sensitivity equations method according to the ANN methodology described above. It was performed using the data from the "training" experiments and it shows good modeling quality. The sufficient modeling quality in both "training" and "validation" experiments sets was reached for main ammonia production processes concentrations.

Hydrogen and methane concentrations after secondary reforming are modeled quite accurately and qualitatively. Hydrogen and methane concentrations after secondary reforming testing are inferior due to systematic modeling errors.

According to the technological regulation of ammonia production, the concentrations are very low, especially the concentrations of $\mathrm{CO}$ and $\mathrm{CO}_{2}$ after the methanation process (Fig. 5-6). The mentioned concentrations according to the chemical reaction equation are residual, therefore it is difficult to accurately model the absolute reaction rates of the concentrations. Nevertheless, $\mathrm{CO}$ and $\mathrm{CO} 2$ concentrations after the methanation process are modeled accurately. Test results for $\mathrm{CO}$ concentrations are good, with slightly worse results for $\mathrm{CO}_{2}$ concentrations.

The figures (Fig. 3-6) show the main modeled concentrations of the ammonia production process obtained using artificial neural networks to model the absolute reaction rates of chemical reactions.

The experimentally measured concentration values shown in the graphs to the modeled curves vary little over time and are slightly noisy. This is due to the factory-run data archiving system, which captures the measured values when they deviate by a fixed amount from the average of the previous value. This is particularly evident when the measured concentrations are in small order of magnitude. 
International Journal of Engineering Applied Sciences and Technology, 2020

Vol. 5, Issue 2, ISSN No. 2455-2143, Pages 8-13

Published Online June 2020 in IJEAST (http://www.ijeast.com)
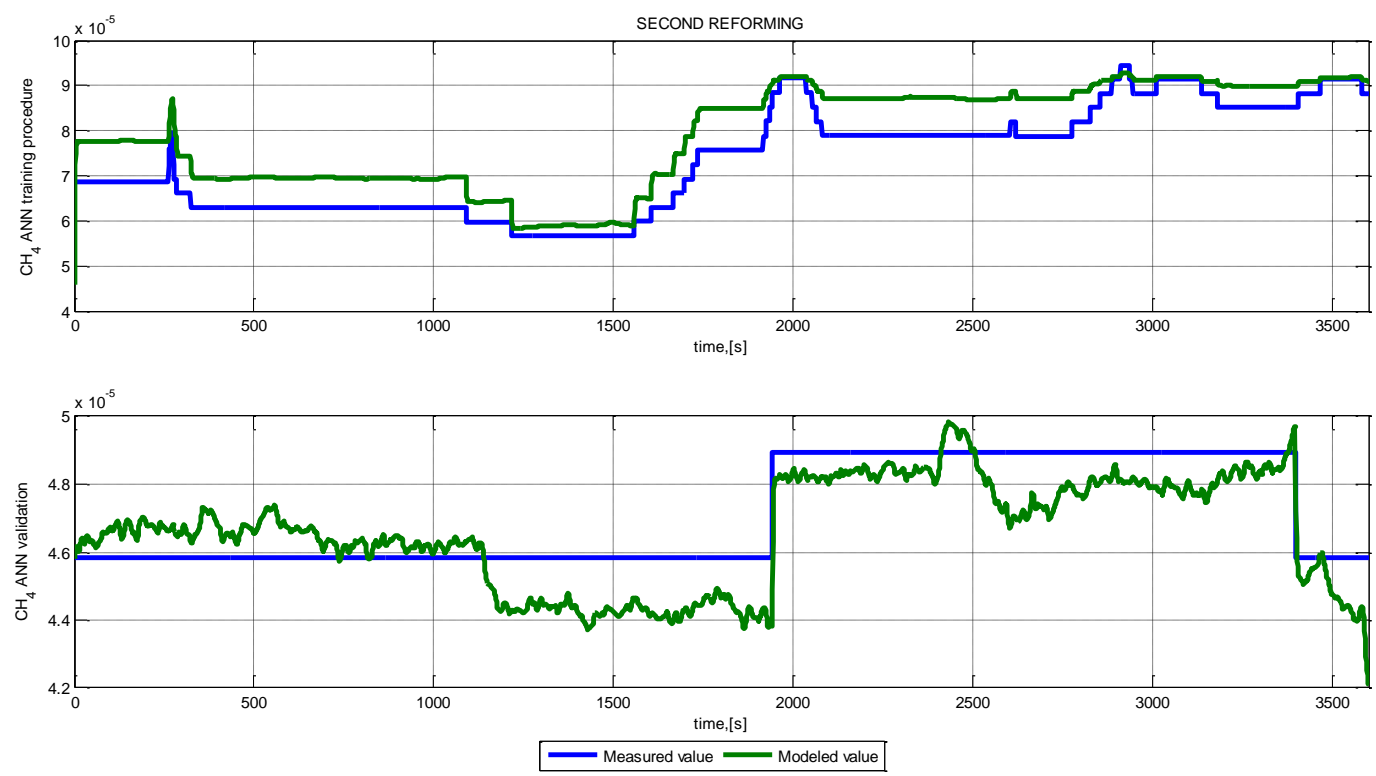

Fig. 3. Results of hybrid model identification: secondary reforming process ANN training and validation experiments
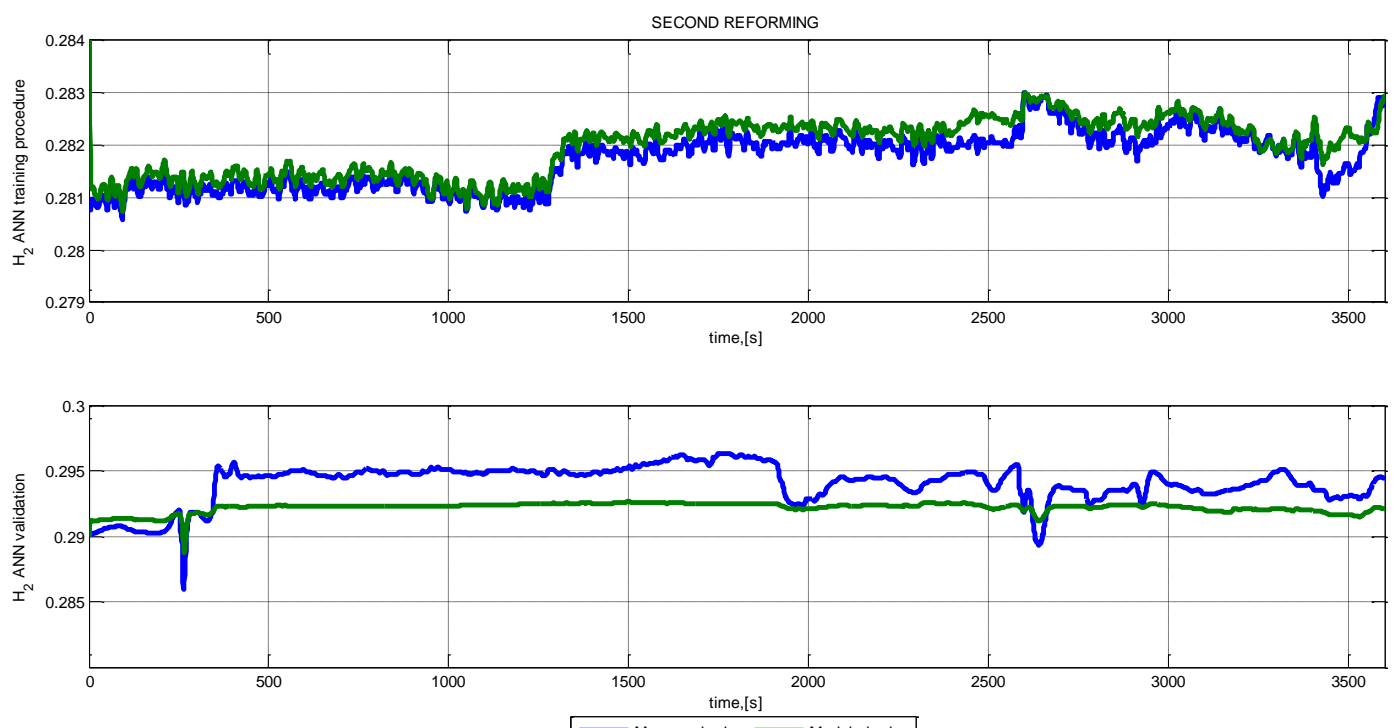

Fig. 4. Results of hybrid model identification: secondary reforming process ANN training and validation experiments 

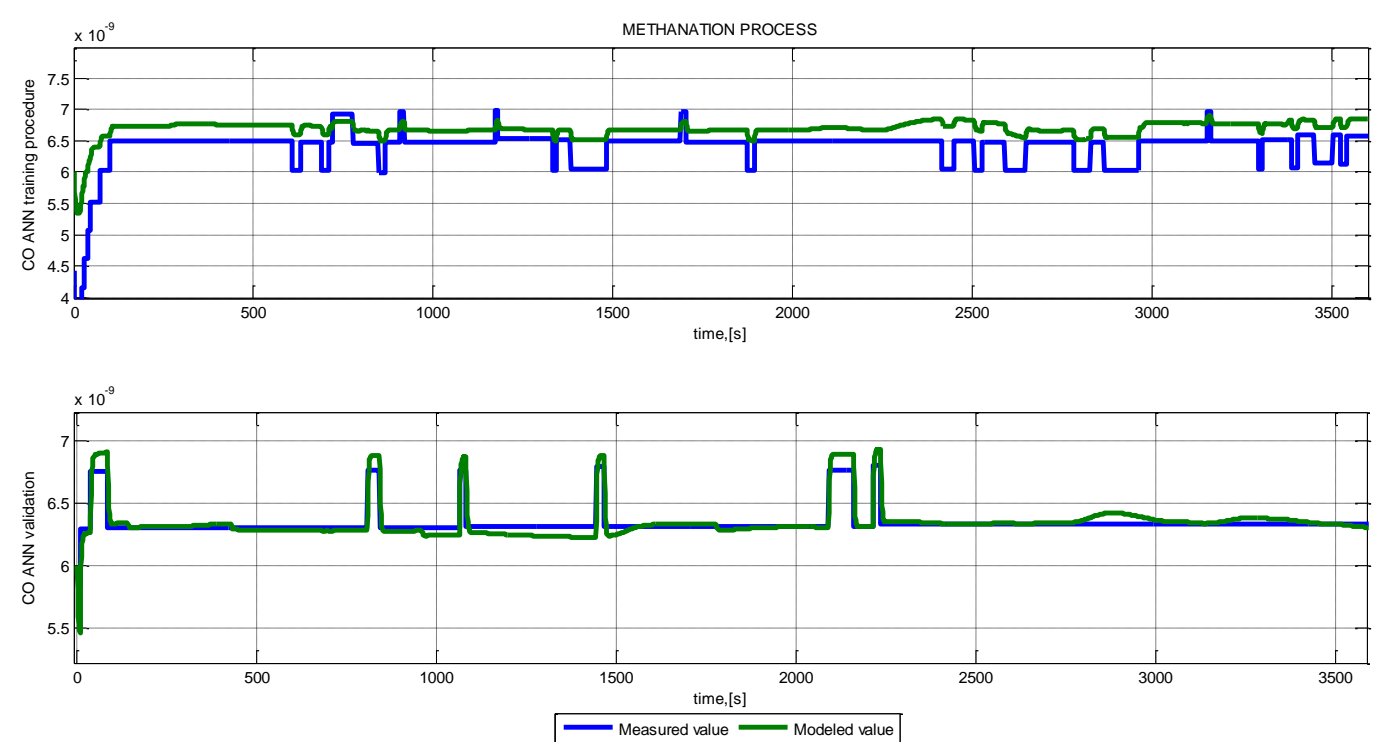

Fig. 5. Results of hybrid model identification: methanation process ANN training and validation experiments
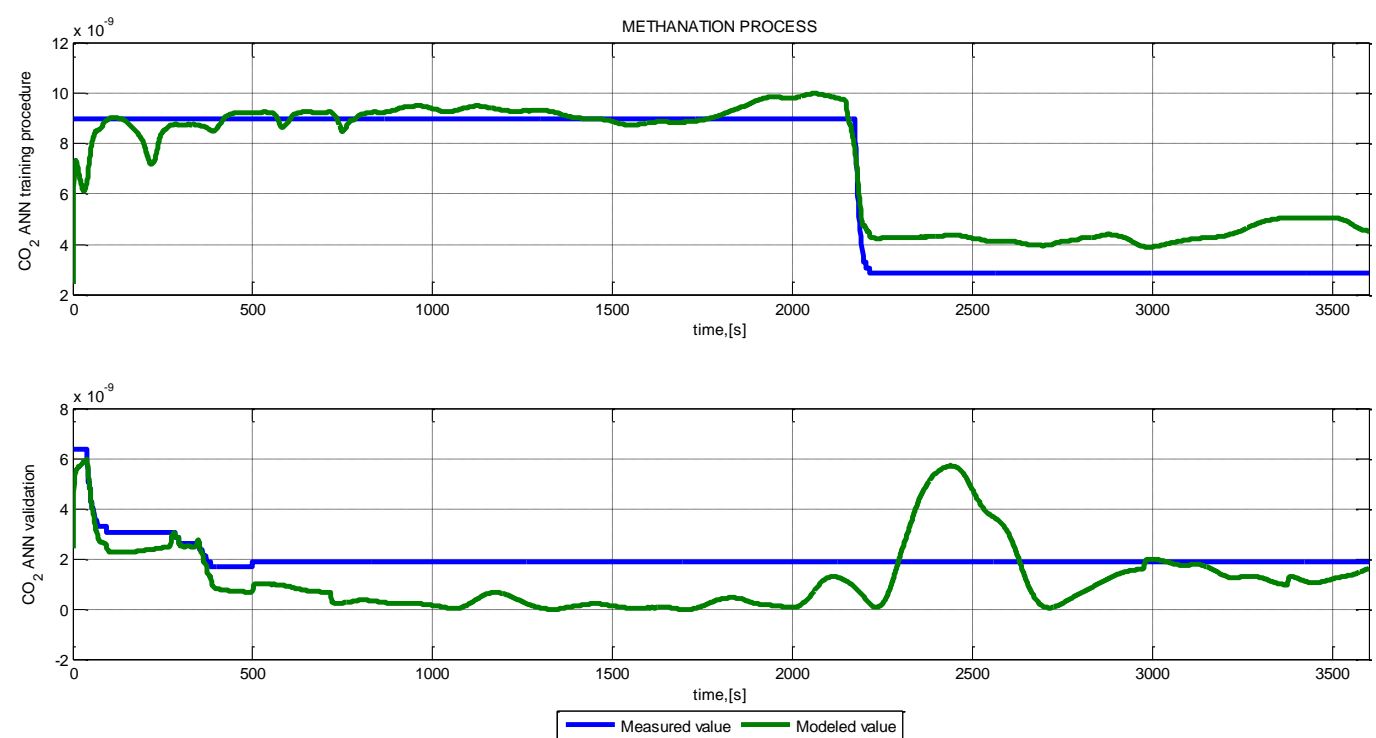

Fig. 6. Results of hybrid model identification: methanation process ANN training and validation experiments

The results of ANN testing also depend on the experimental data used for the testing procedure. In the case where the nature of the experimental data for ANN training differs from the nature of the experimental data used for testing, poorer results for ANN testing are obtained.

The sum of the root mean square error between the modeled and experimental values using experimental test data indicates the quality of trained ANN, i. e., how accurately ANN can predict. The lower the value of the total standard deviation, the better the model predicts. Ideally, it should be zero.

In TABLE $I$ it is shown the root mean square error (RMSE) values between predicted and measured outputs in the "validation set", referred to as the "validation error".
TABLE I. RMSE VALUES FOR HYBRID MODEL.

\begin{tabular}{|c|c|}
\hline Process, concentration & $\begin{array}{c}\text { "validation set" } \\
\text { RMSE }\end{array}$ \\
\hline Secondary reforming, $\left[\mathrm{H}_{2}\right]$ & $2,13 \mathrm{e}-005$ \\
\hline Secondary reforming, $\left[\mathrm{CH}_{4}\right]$ & $7,35 \mathrm{e}-007$ \\
\hline Shift conversion low temperature, $[\mathrm{CO}]$ & $5,47 \mathrm{e}-005$ \\
\hline $\begin{array}{c}\text { Shift conversion average temperature, } \\
{[\mathrm{CO}]}\end{array}$ & $2,80 \mathrm{e}-006$ \\
\hline $\mathrm{CO}_{2}$ removal, $\left[\mathrm{CO}_{2}\right]$ & $6,12 \mathrm{e}-006$ \\
\hline Methanation, $[\mathrm{CO}]$ & $3,83 \mathrm{e}-011$ \\
\hline Methanation, $\left[\mathrm{CO}_{2}\right]$ & $5,12 \mathrm{e}-011$ \\
\hline
\end{tabular}

The model was identified based on experimental data under extreme conditions of the ammonia production process, which are ammonia plants (AB Achema). Measured values are affected by disturbances and errors in control systems and equipment, as well as unit conversion procedures (e.g., [v/ v\%] to [mol / 1]). 


\section{International Journal of Engineering Applied Sciences and Technology, 2020 \\ Vol. 5, Issue 2, ISSN No. 2455-2143, Pages 8-13 \\ Published Online June 2020 in IJEAST (http://www.ijeast.com)}

\section{THE ADEQUACY OF THE MODEL}

In order to evaluate the adequacy of the hybrid model and the significance of the model parameters, a statistical hypothesis testing study is performed. When testing the model adequacy hypothesis, a quantity that characterizes the accuracy of the model is compared with a quantity that characterizes the accuracy of the replication of the experiments. If the errors characterizing the accuracy of the model exceed the experimental errors, then the hypothesis about the adequacy of the model is rejected.

Two sums of squares are compared to check the adequacy of the model:

- Residual dispersion (sum of squares), which characterizes the accuracy of modeling $S_{D}$.

- Repetition dispersion (sum of squares) characterizing the experimental errors $S_{E}$.

The Fisher criterion is used to test the adequacy hypothesis when the significance level is $5 \%$ and the test function of the criterion is as follows:

$$
F=\frac{\frac{S_{D}}{\varphi_{1}}}{\frac{S_{E}}{\varphi_{2}}}
$$

This function is subject to the law of distribution $F$ with numbers of degrees of freedom $\varphi_{1}$ and $\varphi_{2} . \varphi_{1}$ is the number of degrees of freedom in the sum $S_{D}$, while $\varphi_{2}$ is the number of degrees of freedom in the sum $S_{E}$ :

$$
\begin{aligned}
& \varphi_{1}=n-m \\
& \varphi_{2}=n-1
\end{aligned}
$$

where, $n$ is the number of points in the experimental data, while $m$ is the number of model parameters (number of ANN weights).

After calculating the value of the test function $F$, the significance level of the hypothesis test is selected $(5 \%)$ and the critical value $\varepsilon$ is determined from the Fisher distribution tables, corresponding to the calculated number of degrees of freedom.

The hypotheses are then tested:

If $F \leq \varepsilon$ - the model being tested is adequate;

If $F \geq \varepsilon$ - the hypothesis about the adequacy of the model under test is rejected;

Residual and Repetition dispersions are calculated as follows:

$$
S_{D}=\sum_{i=1}^{n}\left(\bar{y}_{e i}-y_{m i}\right)^{2}
$$

where: $y_{e i}$ values, determined as the arithmetic mean $n$ points in the experiment plan. $y_{m i}$ - model values.

$$
S_{E}=\sum_{i=1}^{n}\left(\bar{y}_{e i}-y_{m i}\right)^{2}
$$

where: $y_{e i}$ values, determined as the arithmetic mean $n$ points in the experiment plan. $y_{m i}$ - experiment values.

Statistical analysis of the hybrid model is performed by testing ANN with different experimental data than by training ANN. In the TABLE II the statistical values of the adequacy of the hybrid model and the significance of the model parameters are calculated, the values are determined

\begin{tabular}{|c|c|c|c|c|c|c|c|}
\hline The modeled parameter & $\begin{array}{c}\text { Number of } \\
\text { degrees of } \\
\text { freedom, } \\
\varphi_{1}\end{array}$ & $\begin{array}{c}\text { Number of } \\
\text { degrees of } \\
\text { freedom, } \\
\varphi_{2}\end{array}$ & $\begin{array}{c}\text { Residual } \\
\text { dispersion, } \\
\text { SD }_{\mathrm{D}}\end{array}$ & $\begin{array}{c}\text { Repetition } \\
\text { dispersion, } \\
\mathbf{S}_{\mathrm{E}}\end{array}$ & $\begin{array}{c}\text { The value } \\
\text { of the } \\
\text { objective } \\
\text { function, } F\end{array}$ & $\begin{array}{c}\text { The value of } \\
\text { the Fisher } \\
\text { criterion, } \mathcal{E}\end{array}$ & $\begin{array}{l}\text { Hypothesis } \\
\text { conclusion }\end{array}$ \\
\hline \multicolumn{8}{|c|}{ Secondary reforming } \\
\hline $\mathrm{CH}_{4}$ concentration & 3589 & 3599 & $2,17 \mathrm{e}-010$ & $3,10 \mathrm{e}-010$ & 0,6972 & 1 & The model is adequate \\
\hline $\mathrm{H}_{2}$ concentration & 3589 & 3599 & $4,49 \mathrm{e}-009$ & $1,91 \mathrm{e}-007$ & 0,0236 & 1 & The model is adequate \\
\hline \multicolumn{8}{|c|}{ Shift conversion average temperature } \\
\hline CO concentration & 3589 & 3599 & $2,33 \mathrm{e}-007$ & $2,50 \mathrm{e}-007$ & 0,9348 & 1 & The model is adequate \\
\hline \multicolumn{8}{|c|}{ Shift conversion low temperature } \\
\hline CO concentration & 3589 & 3599 & $3,02 \mathrm{e}-009$ & $3,02 \mathrm{e}-009$ & 0,9986 & 1 & The model is adequate \\
\hline \multicolumn{8}{|c|}{$\mathrm{CO}_{2}$ removal } \\
\hline $\mathrm{CO}_{2}$ concentration & 3589 & 3599 & $6,65 \mathrm{e}-012$ & $6,49 \mathrm{e}-011$ & 0,1022 & 1 & The model is adequate \\
\hline \multicolumn{8}{|c|}{ Methanation } \\
\hline CO concentration & 3589 & 3599 & $8,61 \mathrm{e}-023$ & $2,00 \mathrm{e}-021$ & 0,0429 & 1 & The model is adequate \\
\hline $\mathrm{CO}_{2}$ concentration & 3589 & 3599 & $7,26 \mathrm{e}-018$ & $1,40 \mathrm{e}-017$ & 0,5204 & 1 & The model is adequate \\
\hline
\end{tabular}
and the conclusions of the hypothesis are presented. Based on the results of the performed statistical study, the developed hybrid model is adequate.

TABLE II. CALCULATED VALUES OF THE STATISTICAL STUDY OF THE HYBRID MODEL. 


\section{International Journal of Engineering Applied Sciences and Technology, 2020 \\ Vol. 5, Issue 2, ISSN No. 2455-2143, Pages 8-13 \\ Published Online June 2020 in IJEAST (http://www.ijeast.com)}

\section{CONCLUSION}

Using the sensitivity equation method, the parameters of hybrid models of complex chemical processes were identified. Hybrid models have been developed to simulate the main ammonia production processes in a simulated way.

The developed hybrid models are adequate based on the adequacy study. The models are suitable for use in the development and research of control systems.

\section{REFERENCES}

[1] Xiong Z.H., Zhang J. (2005). Neural network modelbased on-line reoptimisation control of fed-batch processes using a modified iterative dynamic programming algorithm. Chemical Engineering and Processing 44(4), 2005, (pp. 477-484).

[2] Psichogios D.C., Ungar L.H. (1992). A hybrid neural network-first principles approach to process modeling, AIChE Journal 38, 1992, (pp. 1499-1511).

[3] Khorsand K., Dehghan K. (2007). Modeling and simulation of reformer auto-thermal reaction in ammonia unit. Pertrolium \& Coal, Vol. 49(2), 2007, (pp. 64-71).

[4] Dashti A., Khorsand K., Marvast M.A., Kakavand M. (2006). Modeling and simulation of ammonia synthesis reactor. Petroleum \& Coal, Vol. 48(2), 2006, (pp. 15-23).

[5] Simutis R. (1997). Application of hybrid modeling methods for biochemical monitoring and control. Research report presented for habilitation, Kaunas, Technologija, 1997.

[6] Porto W.V., Fogel D.B., Fogel L.J. (1995). Alternative Neural Network Training Methods, IEE Expert, 1995, (pp.16-21).

[7] Na J.G., Chang Y.K., Chung B.H., Lim H.C. (2002). Adaptive optimization of fed-batch culture of yeast by using genetic algorithms. Bioprocess and Biosystems Engineering, Vol. 24, 2002, (pp. 299-308).

[8] Schubert J., Simutis R., Dors M., Havlik I., Lübbert A. (1994). Bioprocess optimization and control: Application of hybrid modeling, Journal of Biotechnology Vol. 35, 1994, (pp. $51-68$ ).

[9] Galvanauskas V., Simutis R. (2007). Software tool for efficient hybrid model-based design of biochemical processes. WSEAS Transactions on Biology and Biomedicine. ISSN 1109-9518. 2007, Vol. 4, Issue 9, (pp.136-144).

[10] Kamesh R., Yamuna Rani K., (2017). Nonlinear control strategies based on Adaptive ANN models: Multi-product semi-batchpolymerization reactor case study. Chemical Engineering Research and Design 121, 2017, (pp. 255 274).

[11] Nguyen D., Gadhamshetty V., Nitayavardhana S., Kumar Khanal S, (2015). Automatic process control in anaerobic digestion technology: A critical review. Bioresource Technology 193, 2015 , (pp. 513 - 522).
[12]Zamaniyan A., Joda F., Behroozsarand A., H. Ebrahimi H. (2013). Application of artificial neural networks (ANN) for modeling of industrial hydrogen plant. International Journal of Hydrogen Energy 38, 2013, p. $6289-6297$.

[13] SC “Achema" (2006). Ammonia technological rules of procedure. - AB “Achema”, 2006. - pp. 8. 